\title{
Correction to: Evolution of Substructure of a Non- equiatomic FeMnCrCo High Entropy Alloy Deformed at Ambient Temperature
}

\author{
A.K. CHANDAN, S. TRIPATHY, M. GHOSH, and S.G. CHOWDHURY
}

https://doi.org/10.1007/s11661-020-05624-4

(C) The Minerals, Metals \& Materials Society and ASM International 2020

\section{Correction to:}

Metallurgical and Materials Transactions A,

Volume 50A, November 2019

https://doi.org/10.1007/s11661-019-05438-z

IN the original article, the second and third column headings are transposed in Table II. Following is the corrected Table II:
Table II. Maximum Schmid Factor for Dislocation Slip and Mechanical Twinning in Different Orientations

\begin{tabular}{lcc}
\hline & \multicolumn{2}{c}{ Schmid Factor } \\
\cline { 2 - 3 } Orientation & Slip & Twinning \\
\hline$\langle 001\rangle$ & 0.41 & 0.24 \\
$\langle 101\rangle$ & 0.41 & 0.47 \\
$\langle 111\rangle$ & 0.27 & 0.31 \\
\hline
\end{tabular}

Publisher's Note Springer Nature remains neutral with regard to jurisdictional claims in published maps and institutional affiliations.
A.K. CHANDAN and S. TRIPATHY are with the Academy of Scientific and Innovative Research (AcSIR), Ghaziabad, 201002, India and also with the Materials Engineering Division, CSIR National Metallurgical Laboratory, Jamshedpur, 831007, India. M. GHOSH and S.G. CHOWDHURY are with the Materials Engineering Division, CSIR National Metallurgical Laboratory. Contact e-mail: ghosh_mnk@yahoo.com,mainakg@nmlindia.org

The original article can be found online at https://doi.org/10.1007/ s11661-019-05438-z.

Article published online January 10, 2020 